\title{
ST Segment Body Surface Isointegral Maps in Patients With Arterial Hypertension
}

\author{
K. KOZLÍKOVÁ ${ }^{1}$, J. MARTINKA ${ }^{1}$, J. BULAS $^{2}$ \\ ${ }^{1}$ Institute of Medical Physics, Biophysics, Informatics and Telemedicine, Faculty of Medicine, \\ Comenius University in Bratislava, Bratislava, Slovak Republic, ${ }^{2}$ The First Department of Internal \\ Medicine, Faculty of Medicine, Comenius University in Bratislava, Bratislava, Slovak Republic
}

Received November 18, 2010

Accepted October 27, 2011

On-line December 20, 2011

\section{Summary}

In this retrospective study we analysed changes of the ST segment in patients with arterial hypertension using multi-lead body surface mapping of the electric heart field as the ST segment often shows non-specific changes and is influenced by many different conditions. We constructed isointegral maps (IIM) of chosen intervals (the first $35 \mathrm{~ms}$, the first $80 \mathrm{~ms}$, and the whole ST segment) in 42 patients with arterial hypertension (with and without left ventricular hypertrophy) and in the control group involving 23 healthy persons. We analysed the position and values of map extrema. Spatial distribution of voltage integrals was similar in the control group and in the "pure" hypertensives. Patients with the left ventricular hypertrophy exhibited shifts of the integral minima. Despite our expectations, the highest extrema values were found in the control group and not in the left ventricular hypertrophy group. The extrema values were similar in all hypertensives, with or without left ventricular hypertrophy. Differences could be explained neither by the influence of the age, nor by the body habitus.

\section{Key words}

Body surface mapping • Isontegral maps • ST segment • Arterial hypertension • Left ventricular hypertrophy

\section{Corresponding author}

Katarína Kozlíková, Institute of Medical Physics, Biophysics, Informatics and Telemedicine, Faculty of Medicine CU, Sasinkova 2, 81372 Bratislava, Slovak Republic.

E-mail: katarina.kozlikova@fmed.uniba.sk

\section{Introduction}

The ST segment on the electrocardiogram is the interval between the end of the QRS complex and the beginning of the $\mathrm{T}$ wave. It corresponds to the plateau phase of the ventricular transmembrane action potential. Under normal conditions, the transmembrane voltage changes slowly during this phase and remains at approximately the same level in all ventricular myocardial cells. As a result, only small voltage gradients are present; therefore, the ST segment is normally nearly flat and approximately at the same level with the TP segment; that means, it is isoelectric (Rautaharju et al. 2009).

Abnormalities in the ST segment and T wave are caused by an abnormal voltage gradient during plateau and rapid repolarisation phases of the action potential and by changes in the sequence of repolarisation that may occur both with and without abnormal voltage gradients. These abnormalities are often associated with well defined anatomic, pathological, physiological, and pharmacological events. For example, ventricular hypertrophy is associated with changes in the shape and duration of the ventricular action potential of isolated ventricular cells, particularly on the endocardial surface. These changes may contribute to ST segment deviations and are independent of the secondary QRS amplitude changes and of the QRS complex prolongation (Rautaharju et al. 2009).

The point where the ST segment begins is commonly called the $\mathrm{J}$ point. This can be normally elevated in leads $V_{1}, V_{2}$, and $V_{3}$, especially in men less than 40 years old, approximately till $0.3 \mathrm{mV}$. The amplitude decreases in men with age while in women it 
Table 1. Blood pressure and selected echocardiographic characteristics of patient groups.

\begin{tabular}{lccccc}
\hline Group & $\begin{array}{c}\text { BPS } \\
{[\mathbf{m m H g}]}\end{array}$ & $\begin{array}{c}\text { BPD } \\
{[\mathbf{m m H g}]}\end{array}$ & $\begin{array}{c}\text { LVM } \\
{[\mathbf{g}]}\end{array}$ & $\begin{array}{c}\text { LVMI } \\
{\left[\mathbf{g} \cdot \mathbf{m}^{-2}\right]}\end{array}$ & RWT \\
\hline$H T-$ all & $147 \pm 17$ & $93 \pm 7$ & $218 \pm 40$ & $108 \pm 15$ & $0.43 \pm 0.05$ \\
$H T-$ men & $142 \pm 16$ & $92 \pm 8$ & $231 \pm 34$ & $114 \pm 16$ & $0.44 \pm 0.06$ \\
$H T-$ women & $157 \pm 14$ & $97 \pm 6$ & $195 \pm 41^{*}$ & $99 \pm 7^{\#}$ & $0.41 \pm 0.04$ \\
LVH-all & $157 \pm 23$ & $94 \pm 15$ & $318 \pm 70^{*}$ & $156 \pm 30^{*}$ & $0.49 \pm 0.08^{*}$ \\
LVH-men & $153 \pm 22$ & $98 \pm 8$ & $348 \pm 65^{*}$ & $164 \pm 33^{*}$ & $0.49 \pm 0.07$ \\
LVH-women & $161 \pm 24$ & $91 \pm 19$ & $279 \pm 56^{*}$ & $145 \pm 24^{*}$ & $0.49 \pm 0.11^{*}$ \\
\hline
\end{tabular}

BPS: systolic blood pressure, BPD: diastolic blood pressure; ${ }^{*} p<0.05$ group HT against group LVH, ${ }^{*} p<0.05$ men against women of the same group

remains relatively unchanged, approximately $0.15 \mathrm{mV}$ (Macfarlane 2001, Surawicz and Parikh 2003, Macfarlane et al. 2011). The border between the end of the ST segment and the beginning of the $\mathrm{T}$ wave is often difficult to find, but the ST segment abnormalities may occur with or without the $\mathrm{T}$ wave abnormalities (Rautaharju et al. 2009). In a standard electrocardiographic examination, the ST segment is a useful marker of ischemia, but it can help to detect also left ventricular hypertrophy and other diseases; for example, chronic pressure overload as in arterial hypertension often results in concentric left ventricular hypertrophy (Macfarlane et al. 2011).

The aim of this retrospective study was to find out, whether it is possible to detect any changes on body surface isointegral maps of the ST segment in patients with arterial hypertension, without and with left ventricular hypertrophy. The major advantage of body surface potential mapping over the conventional 12-lead electrocardiogram is that they allow exploring the entire chest surface and thus provide all the information on the cardiac electric field available at the body surface (Medvegy et al. 2002, Kittnar and Mlček 2010).

We expected higher positive and deeper negative values of voltage-time integrals of the ST segment and its portions in hypertensive patients with left ventricular hypertrophy compared to controls and/or to hypertensive patients without hypertrophy as the left ventricular hypertrophy can cause abnormal elevation of the ST segment mainly in standard leads $\mathrm{V}_{1}$ to $\mathrm{V}_{3}$ and abnormal depression mainly in standard leads $\mathrm{V}_{5}$ and $\mathrm{V}_{6}$ (Khan 2003).

\section{Methods}

\section{Patients}

We studied 42 patients with arterial hypertension
( 25 men, 17 women, mean age $53 \pm 12 \mathrm{y}$, range $25-76 \mathrm{y}$ ). All of them were hospitalised for cardiovascular reasons. The body surface potential mapping was performed during the first days after admission; altogether in more than 75 patients. Patients with manifested clinical signs of ischemia, conduction disturbances, renal insufficiency, diabetes and/or pulmonary diseases were excluded from this study.

The diagnosis of arterial hypertension was based on repeated clinical examinations with the systolic blood pressure higher than $140 \mathrm{mmHg}$ and/or the diastolic blood pressure higher than $90 \mathrm{mmHg}$. This diagnosis was established at least 5 years before admission to the hospital. All patients were treated according to the guidelines with combination therapy used in most patients (Mancia et al. 2007). Mean systolic pressure of these patients at the time of map recording was $153 \pm 21 \mathrm{mmHg}$; mean diastolic pressure was $93 \pm 12 \mathrm{mmHg}$ (Table 1). Patients were divided into two subgroups according to the presence or absence of the left ventricular hypertrophy based on echocardiographic evaluations. Group HT involved 17 patients without left ventricular hypertrophy (11 men, 6 women, mean age $50 \pm 13 \mathrm{y}$, range 25-76 y). Group LVH involved 25 patients with left ventricular hypertrophy ( 15 men, 10 women, mean age $54 \pm 12 \mathrm{y}$, range 32-72 y).

The left ventricular mass LVM [g] was calculated according to the formula

$\mathrm{LVM}=1.04 \cdot\left[(\operatorname{IVSd}+\mathrm{LVPWd}+\mathrm{LVIDd})^{3}-\mathrm{LVIDd}^{3}\right]-13.6$,

where IVSd is the thickness of the interventricular septum [cm], LVPWd is the thickness of the left ventricular posterior wall $[\mathrm{cm}]$, LVIDd is the internal diameter of the left ventricle $[\mathrm{cm}]$, all measured in 
diastole (Bulas et al. 1998). The left ventricular hypertrophy was based on the left ventricular mass index LVMI $>109 \mathrm{~g} / \mathrm{m}^{2}$ for women and LVMI $>134 \mathrm{~g} / \mathrm{m}^{2}$ for men, where

$$
\mathrm{LVMI}=\frac{\mathrm{LVM}}{\mathrm{BSA}}
$$

Body surface area was calculated according to Mosteller formula (Mosteller 1987)

$$
\mathrm{BSA}=\sqrt{\frac{\mathrm{m} \cdot \mathrm{h}}{3600}},
$$

where $\mathrm{m}$ is the body mass $[\mathrm{kg}]$ and $\mathrm{h}$ is the body height [cm].

In the LVH group, 17 patients had concentric hypertrophy $(\mathrm{RWT}>0.45)$ and 8 patients had eccentric hypertrophy. RWT is the relative wall thickness

$$
\text { RWT }=\frac{\text { IVSDd }+ \text { LVPWd }}{\text { LVIDd }}
$$

Selected echocardiographic characteristics of all patient groups, all obtained in M-mode and measured by one investigator (co-author), are given in Table 1.

The control group ( $\mathrm{C}$ group) involved 23 healthy people (14 men, 9 women, mean age $34 \pm 13 \mathrm{y}$, range 22-56 y). None of the controls had signs of cardiovascular diseases or cardiovascular risk; all had normal 12-lead standard electrocardiographic and echocardiographic findings as well as blood pressure values.

\section{Body surface potential mapping}

Unipolar electrocardiograms for body surface potential mapping were registered using the limited 24lead system after Barr (Barr et al. 1971) and processed using the mapping system ProCardio (Rosík et al. 1997). All data were registered in supine position during normal expiration.

Linear baselines were taken through TP segments in each electrocardiogram. The offset of the QRS complex (the J point) and the offset of the T wave were established manually from the root mean square signal. The limiting points were set at the end of a sequence of decreasing values when starting from the middle of the QRS complex or from the middle of the
T wave. To ensure the reproducibility of data processing, all mapping registrations and signal processing were done by the same investigator (the author) and based on the same procedures and algorithms.

The onset of the $\mathrm{T}$ wave was established as the first 3/8 of the ST interval (Ikeda et al. 1985, Kozlíková 1990). Isointegral maps (IIM) were constructed as distributions of voltage time integrals over chosen time intervals. We constructed and analysed isointegral maps of following intervals: the first $35 \mathrm{~ms}$ of the ST segment (IIM J35), the first $80 \mathrm{~ms}$ of the ST segment (IIM J80), and the whole ST segment (IIM ST). Mean isointegral maps were calculated from single beat maps ( $9 \pm 3$ beats) according to the heart rate for each subject. We analyzed values of maxima and minima and their locations as well as peak-to-peak values (maximum minus minimum) in the mean maps.

\section{Statistical methods}

All data were tested for normal distribution using the Shapiro-Wilk test (smaller sample size) or by skewness and kurtosis (larger sample size; Kozlíková and Martinka 2009). Normally distributed data are expressed in form of average plus minus one standard deviation. They were compared using either the analysis of variance with appropriate post hoc tests or the t-test. Data, that were not distributed normally, are expressed in form of median with the $95 \%$ confidence interval. They were compared using either Kruskall-Wallis test with the Dunn's test or the Mann-Whitney test (Altmann 1999). Calculations were performed using the statistical package Statgraphics Plus (Statgraphics 1997). Statistically significant differences were considered for $\mathrm{p}<0.05$.

\section{Results}

All electrocardiographic recordings were performed during normal sinus rhythm with mean heart rate of all subjects $67 \pm 10 \mathrm{~min}^{-1}$. There were no statistically significant differences of the heart rate among the examined groups (Table 2). The overall QRS duration was $93 \pm 11 \mathrm{~ms}$. The only statistically significant difference was found between men and women in the control group (Table 2). The overall QT interval duration was $399 \pm 34 \mathrm{~ms}$ and overall ST segment duration was $115 \pm 13 \mathrm{~ms}$ without any statistical differences among the groups (Table 2). 
Table 2. Selected electrocardiographic characteristics of examined groups.

\begin{tabular}{lccccc}
\hline Group & $\begin{array}{c}\text { Heart rate } \\
{\left[\mathbf{m i n}^{-1}\right]}\end{array}$ & $\begin{array}{c}\text { QRS duration } \\
{[\mathbf{m s}]}\end{array}$ & $\begin{array}{c}\text { QT duration } \\
{[\mathbf{m s}]}\end{array}$ & $\begin{array}{c}\text { ST segment } \\
\text { duration [ms] }\end{array}$ & $\begin{array}{c}\text { Cornell voltage } \\
{[\mathbf{m V}]}\end{array}$ \\
\hline C-all & $65 \pm 8$ & $91 \pm 9$ & $395 \pm 27$ & $114 \pm 11$ & $1.1 \pm 0.6$ \\
C-men & $65 \pm 7$ & $95 \pm 9$ & $390 \pm 23$ & $111 \pm 8$ & $1.2 \pm 0.8$ \\
C-women & $67 \pm 10$ & $86 \pm 6^{\#}$ & $402 \pm 34$ & $118 \pm 13$ & $1.0 \pm 0.4$ \\
HT-all & $69 \pm 10$ & $93 \pm 11$ & $394 \pm 39$ & $113 \pm 15$ & $1.5 \pm 0.4$ \\
$H T-$ men & $69 \pm 13$ & $93 \pm 10$ & $384 \pm 35$ & $109 \pm 15$ & $1.5 \pm 0.4$ \\
$H T-$ women & $68 \pm 5$ & $93 \pm 14$ & $412 \pm 43$ & $119 \pm 14$ & $1.3 \pm 0.4$ \\
LVH-all & $67 \pm 11$ & $94 \pm 13$ & $407 \pm 36$ & $118 \pm 14$ & $2.1 \pm 0.8^{*}$ \\
LVH-men & $70 \pm 12$ & $92 \pm 10$ & $396 \pm 35$ & $114 \pm 13$ & $2.0 \pm 0.9$ \\
LVH-women & $63 \pm 9$ & $95 \pm 15$ & $422 \pm 33$ & $123 \pm 14$ & $2.1 \pm 0.8^{*}$ \\
\hline
\end{tabular}

${ }^{*} \mathrm{p}<0.05$ group HT or group $\mathrm{C}$ against group $\mathrm{LVH}_{,}{ }^{\#} \mathrm{p}<0.05$ men against women of the same group
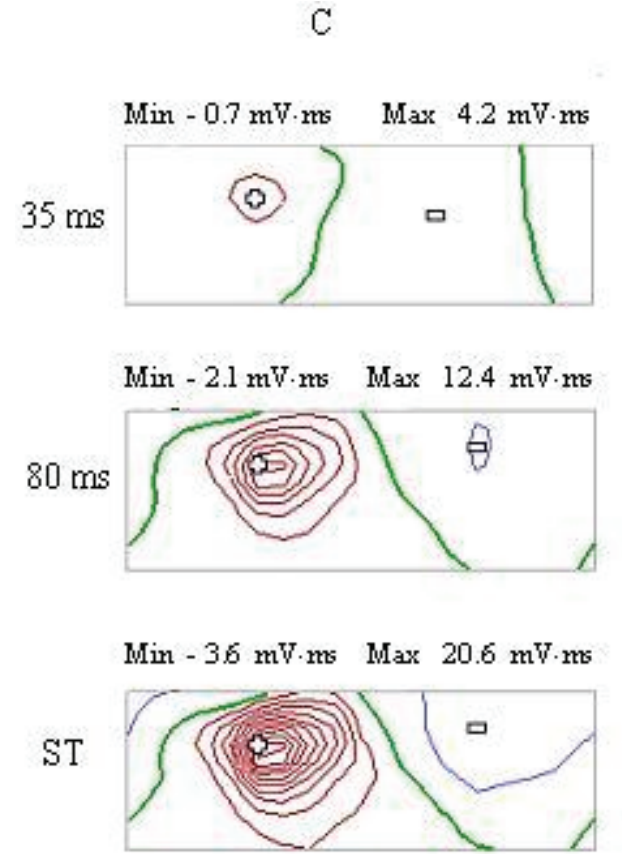

HT

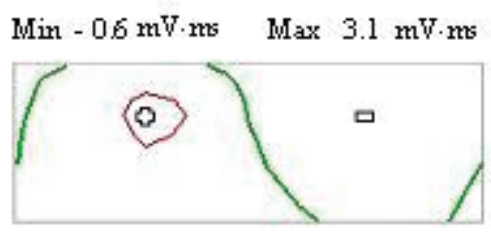

Min $-18 \mathrm{mV} \cdot \mathrm{ms} \quad$ Max $9.5 \mathrm{mV} \cdot \mathrm{ms}$

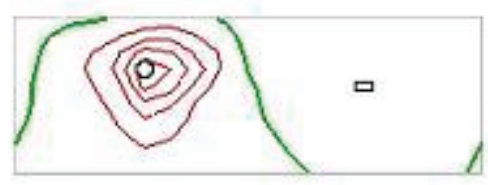

Min $-29 \mathrm{mV} \cdot \mathrm{ms} \quad$ Max $15.3 \mathrm{mV} \cdot \mathrm{ms}$

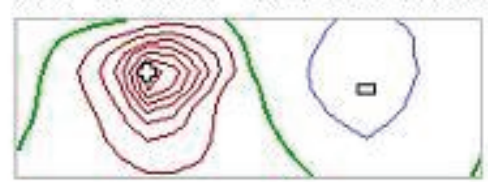

$\mathrm{LVH}$

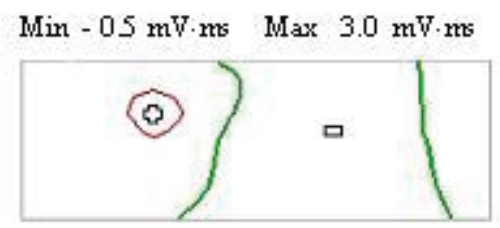

$\mathrm{Min}-1.4 \mathrm{mV} \cdot \mathrm{ms} \quad \mathrm{Max} 8.8 \mathrm{mV} \cdot \mathrm{ms}$

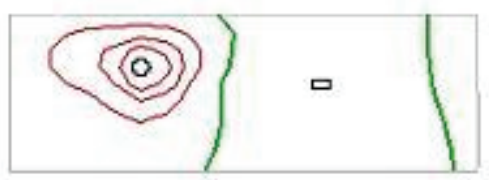

Min $-2.4 \mathrm{mV} \cdot \mathrm{ms} \quad \mathrm{Max} 15.0 \mathrm{mV} \cdot \mathrm{ms}$

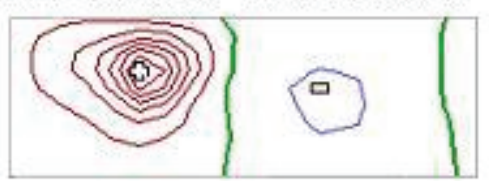

Fig. 1. Group mean isointegral maps of the ST segment and its portions. Maps represent the chest surface divided along the right axillary line. Isointegral lines mark places with equal value of voltage time integrals, maximum and minimum are marked by pertinent sign. Step between isointegral lines is $2.0 \mathrm{mV} \cdot \mathrm{ms}$.

The Cornell voltage was used to evaluate the left ventricular hypertrophy from the standard 12-lead electrocardiogram (Macfarlane et al. 2011). In the LVH group, the sum of voltages $\mathrm{RaVL}+\mathrm{SV}_{3}$ was higher than $2.0 \mathrm{mV}$ in 7 of 11 women, but it was higher than $2.8 \mathrm{mV}$ only in 1 of 14 men. The sum of voltages was lower than the limit in any other examined subject of this study (Table 2).

Concerning the maps, the mean distribution of integrals was smooth bipolar in all intervals of all examined groups (Figure 1). The maxima were always concentrated in a relatively small area over the lower sternum, in the vicinity of the standard lead $\mathrm{V}_{2}$, regardless the group and the examined portion of the ST segment (Figure 2).

The minima covered much larger areas. In the controls and in the HT group, they were mainly located along the spine, but also scattered over the anterior chest. In the IIM ST, the minima in the HT group were shifted significantly downwards compared to the controls. In the LVH group, the minima were located mainly in the precordium, close to the positions of the standard leads 
$\mathrm{V}_{5}$ and $\mathrm{V}_{6}$, but also scattered over the back. In the IIM $\mathrm{ST}$, the minima in the LVH group were shifted significantly downwards compared to the controls. No statistically significant differences were found between the groups HT and LVH in the positions of extrema
(Figure 2). The only gender difference was found in the location of the IIM ST minima in the LVH group; the minima in the men were shifted slightly but significantly downwards compared to the women.

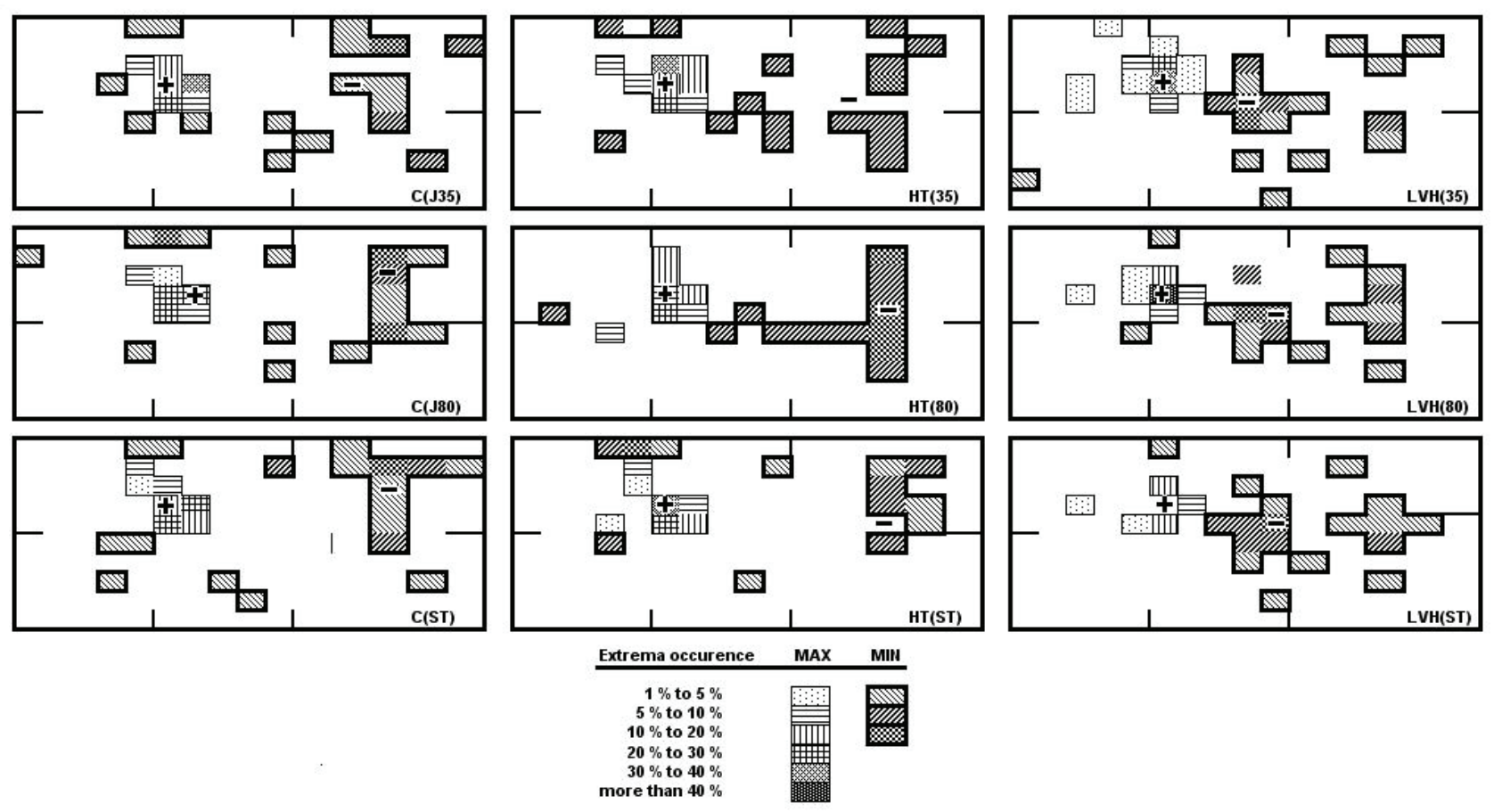

Fig. 2. The positions of the maxima and minima in individual maps of all examined groups and all examine portions of the ST segment. The short vertical lines in every map depict the positions of the sternum and the left mid-axillary line, respectively. The short horizontal line depicts the approximate position of the $5^{\text {th }}$ intercostal space. The plus and the minus signs display the median positions of the maximum and the minimum, respectively.

Table 3. Extrema values of portions of the ST segment.

\begin{tabular}{lccc}
\hline Group & Maximum & Minimum & Peak-to-peak \\
\hline & & IIM J35 $[\mathrm{mV} \cdot \mathrm{ms}]$ & \\
$C$ & $4.0(3.1 ; 6.5)$ & $-0.9(-1.3 ;-0.8)$ & $5.0(3.9 ; 7.8)$ \\
$H T$ & $3.5(2.5 ; 4.8)$ & $-1.0(-1.2 ;-0.7)$ & $4.5(3.4 ; 5.8)$ \\
$L V H$ & $3.6(2.1 ; 4.0)$ & $-0.9(-1.2 ;-0.8)$ & $4.6(3.2 ; 5.4)$ \\
& & & \\
$C$ & $11.8(8.6 ; 21.2)$ & $-2.8(-3.3 ;-2.2)$ & $15.3(10.8 ; 20.4)$ \\
$H T$ & $9.4(7.4 ; 12.8)$ & $-2.0(-2.9 ;-1.7)$ & $11.2(9.3 ; 14.5)$ \\
$L V H$ & $9.5(5.6 ; 11.6)$ & $-2.3(-2.8 ;-1.9)$ & $11.7(8.4 ; 13.8)$ \\
& & IIM ST $[\mathrm{mV} \cdot \mathrm{ms}]$ & \\
$C$ & & $-4.5(-5.3 ;-3.7)$ & $28.9(20.8 ; 36.6)$ \\
$L V H$ & $24.1(16.5 ; 31.7)$ & $-3.5(-4.4 ;-2.4)$ & $18.1(14.4 ; 24.2)$ \\
& $14.7(12.3 ; 20.7)$ & $-3.4(-4.5 ;-2.8)$ & $19.5(14.6 ; 25.6)$
\end{tabular}

${ }^{*} \mathrm{p}<0.05$ group LVH against group C 
The highest extrema (minima taken in their absolute value) were found in the control group (Table 3). Significant differences were between the LVH group and the controls in the IIM ST maxima and in the peak-topeak values. When comparing the men separately, both HT and LVH groups had significantly lower maxima and peak-to-peak values than the controls in all examined maps. No significant differences were found between the women's groups. What concerns the gender differences, the men had always higher mean values then the women (minima taken in their absolute value). In the control group, it concerned all maps and all extrema. In the HT group, the maxima differed in all maps; the peak-to-peak values only in the IIM J80 and IIM ST. No significant differences were found in LVH group between men and women. No significant differences were found between the HT and the LVH group in any values of extrema.

\section{Discussion}

The ST segment portions were chosen for three reasons: the initial part of the ST segment (the first $35 \mathrm{~ms}$ ) may be dominantly affected by the eventual J point shift; the first $80 \mathrm{~ms}$ were chosen to include a substantial part of the ST segment excluding the involvement of the T wave; and the whole ST segment to analyse it regardless its duration. The isointegral maps were chosen because they stress small voltage changes that last for longer time.

The distribution of potentials in the isointegral ST segment maps (IIM ST) of the control group were in accordance with data published in a previous study involving 20 healthy subjects (Ikeda et al. 1985). However, their values of extrema were even higher than in our study (maximum $36.0 \pm 9.1 \mathrm{mV} \cdot \mathrm{ms}$; minimum $-8.0 \pm 6.5 \mathrm{mV} \cdot \mathrm{ms})$. Higher voltages in the precordial leads of Japanese people are in accordance with published data (Macfarlane et al. 2011).

In another study (Slavíček et al. 2001), the same parts of the ST segment as in our study (IIM J35 and IIM J80) were analysed in 24 healthy persons (age 20-36 years). Values of maxima did not differ from our values, but the minimal values were deeper (J35: $-1.6 \pm 0.5 \mathrm{mV} \cdot \mathrm{ms} ; \mathrm{J} 80:-5.3 \pm 0.5 \mathrm{mV} \cdot \mathrm{ms}$ ).

The gender differences found in our study are supported not only by standard electrocardiograms mentioned in the Introduction, but also by isopotential maps of the ST segment, $80 \mathrm{~ms}$ after the QRS offset (Green et al. 1985). Men had slightly higher positive voltages than women. The amplitudes decreased with age more slowly in women than in men. Negative potentials were recorded in vicinity of standard leads $V_{5}$ and $V_{6}$ in both women over 50 years and men over 60 years.

The main positions of maxima and minima in our isointegral maps are in accordance also with isopotential maps of the ST segment of healthy subjects and patients with left ventricular hypertrophy that were analyzed approximately $50 \mathrm{~ms}$ after the $\mathrm{J}$ point (Kornreich et al. 1989). They appeared in areas corresponding with our findings.

In this study, the age of the analysed groups was different, controls were younger. To avoid the age influence, we created a subgroup of 6 male controls with more comparable age $36 \pm 14 \mathrm{y}$, but still significantly younger than patients (the mean age of the original male subgroup was $30 \pm 12 \mathrm{y}$ ). The statistically significant differences of the extrema values disappeared; the extrema medians of male controls decreased by $0 \%$ to about $15 \%$. Therefore, we cannot exclude the influence of a small sample size instead of a really existing difference. On the other side, a statistically significant upward shift of the control's minima in the IIM ST occurred (approximately to the $3^{\text {rd }}$ intercostal space) compared to both male groups of patients - HT and LVH.

As we expected higher values of ST segment, the increased age of patients cannot be the only reason of our results. Decreased values in patients could be also partially due to their significantly higher body mass index against controls $\left(29.4 \pm 5.1 \quad \mathrm{~kg} \cdot \mathrm{m}^{-2}\right.$ versus $23.9 \pm$ $3.1 \mathrm{~kg} \cdot \mathrm{m}^{-2}$ ). The female patients were more obese than the males $\left(31.2 \pm 6.2 \mathrm{~kg} \cdot \mathrm{m}^{-2}\right.$ versus $\left.28.1 \pm 3.7 \mathrm{~kg} \cdot \mathrm{m}^{-2}\right)$, therefore, this does not sufficiently explain our findings, as body habitus of women appears to be an unimportant variable with regard to the body surface maps despite the significant effects of body habitus of men on both voltage and distribution pattern (Green et al. 1985).

In spite of our expectations, we found that patients with arterial hypertension (regardless the left ventricular hypertrophy) had ,flatter" isointegral maps of the whole ST segment, as well as of its portions. Spatial distribution of voltage integrals was similar in controls and in "pure" hypertensives, while the extrema values were closer in the HT and the LVH groups. Patients with left ventricular hypertrophy exhibited shifts of integral minima. Differences could be explained neither by the influence of the age, nor by the body habitus. Therefore, more specialised studies are needed to explain these findings, for example, to compare patients in the 
beginning stage of arterial hypertension to those with longer lasting arterial hypertension or to evaluate the influence of different drugs on maps.

\section{Conflict of Interest}

There is no conflict of interest.

\section{Acknowledgements}

This study was partially supported by the grant KEGA 004UK-4/2011 from the Ministry of Education, Science, Research and Sport, Slovak Republic. These results were partially presented at the $4^{\text {th }}$ Young Biomedical Engineers and Researchers Conference - YBERC 2010, held in Košice (Slovak Republic) on July 1-3, 2010.

\section{References}

ALTMAN GG: Practical Statistics for Medical Research. Chapmann\&Hall/CRC, Boca Raton, 1999, 611 pp.

BARR RC, SPACH MS, HERMAN-GIDDENS GS: Selection of the number and positions of measuring locations for electrocardiography. IEEE Trans Biomed Eng 18: 125-138, 1971.

BULAS J, MURÍN J, KOZLÍKOVÁ K: Echocardiographic characteristics of left ventricular hypertrophy. Cardiology 7: 92-98, 1998.

GREEN LS, LUX RL, HAWS CHW, WILLIAMS RR, HUNT SC, BURGESS MJ: Effects of age, sex, and body habitus on QRS and ST-T potential maps of 1100 normal subjects. Circulation 71: 244-253, 1985.

IKEDA K, KUBOTA I, YASUI S: Effects of lung volume on body surface electrocardiogram. Jap Circ J 49: 284-291, 1985.

KELLEROVÁ E, SZATHMÁRY V, KOZMANN G, HARASZTI K, TARJÁNYI Z: Spontaneous variability and reactive postural beat-to-beat changes of integral ECG body surface potential maps. Physiol Res 59: 887-896, 2010.

KHAN MG: Rapid ECG Interpretation. Humana Press Inc., Totowa, New Jersey, 2003, 424 pp.

KITTNAR O, MLČEK M: Analysis of the electrical heart field. Physiol Res 59 (Suppl 1): S19-S24, 2010.

KORNREICH F, MONTAGUE TJ, RAUTAHARJU PM, KAVADIAS M, HORACEK BM, TACCCARDI B: Diagnostic body surface potential map patterns in left ventricular hypertrophy during PQRST. Am J Cardiol 63: 610-617, 1989.

KOZLÍKOVÁ K: Surface integral maps, their characteristics and methods of quantitative analysis. (in Slovak) Brat Med J 91: 815-823, 1990.

KOZLÍKOVÁ K, MARTINKA J: The Essentials of Biomedical Measurement Processing II. (in Slovak) Asklepios, Bratislava, 2009, 204 pp.

MACFARLANE PW: Age, sex, and the ST amplitude in health and disease. J Electrocardiol 34 (Suppl): 235-241, 2001.

MACFARLANE PW, VAN OOSTEROM A, PAHLM O, KLIGFIELD P, JANSE M, CAMM J (eds): Comprehensive Electrocardiology. Springer-Verlag, London, 2011, 2310 pp.

MANCIA G, DE BACKER G, DOMINICZAK A, CIFKOVA R, FAGARD R, GERMANO G, GRASSI G, ET AL.: 2007 Guidelines for the management of arterial hypertension. The Task Force for the Management of Arterial Hypertension of the European Society of Hypertension (ESH) and of the European Society of Cardiology (ESC). Eur Heart J 28: 1462-1536, 2007.

MEDVEGY M, DURAY G, PINTÉR A, PRÉDA I: Body surface potential mapping: historical background, present possibilities, diagnostic challenges. Ann Noninvasive Electrocardiol 7: 139-151, 2002.

MOSTELLER RD: Simplified calculation of body-surface area. $N$ Engl J Med 317: 1098, 1987.

RAUTAHARJU PM, SURAWICZ B, GETTES LS, BAILEY JJ, CHILDERS R, DEAL BJ, GORGELS A, ET AL.: AHA/ACCF/HRS recommendations for the standardization and interpretation of the electrocardiogram. Part IV: The ST segment, T and U waves, and the QT interval. J Am Coll Cardiol 53: 982-991, 2009.

ROSÍK V, TYŠLER M, TURZOVÁ M: Portable device for ECG mapping. In: Proceedings of International Conference of Measurement. I FROLLO, A PLAČKOVÁ (eds), SAV, Bratislava, 1997, pp 367-370.

SLAVÍČEK J, KITTNAR O, NOVÁK V, TREFNÝ Z, HORÁČEK BM: ECG body surface isointegral and isoarea maps (BSM) in 30 and 60-years-old healthy humans. Sb Lék 102: 369-374, 2001. 
SURAWICZ B, PARIKH SR: Differences between ventricular repolarization in men and women: description, mechanism and implications. Ann Noninvasive Electrocardiol 8: 333-340, 2003.

Statgraphics ${ }^{\circledR}$ plus, version 3 for Windows. User manual. Manugistics, Inc., Rockville, 1997. 